\title{
The Opticker's Apprentice Training In Optics Within Traditional Non-Optics Curricula
}

\section{Donald O'Shea}

Donald C O'Shea, "The Opticker's Apprentice Training In Optics Within Traditional Non-Optics Curricula," Proc. SPIE 0978, 1988 Intl Conf on Education in Optics, (27 April 1989); doi: 10.1117/12.948586

Event: 32nd Annual International Technical Symposium on Optical and United States 


\title{
The Opticker's Apprentice \\ Training in Optics within Traditional Non-Optics Curricula
}

\author{
Donald C. O'Shea \\ School of Physics \\ Georgia Institute of Technology \\ Atlanta, GA 30332-0430
}

\section{Introduction}

Historically most training in optics was done at the graduate level. It was assumed that a basic grounding in physics or engineering was required and that the demand could be met by the established programs. Recently, however, with the emergence of an entire new optical technology, the training in optics has taken place at a number of different levels. As doctoral research encompassed devices and techniques that were the basis of this new technology, newly minted PhD's, including the author, joined the faculties in the usual fields of studies, but brought with them their enthusiasm for and knowledge of things optical. Going beyond the usual sophomore sequence on image formation and the standard single upper level course in geometrical and physical optics, these new faculty members, began to develop new courses and laboratories that brought some of their optics into the standard undergraduate curriculum.

This paper is an attempt to assess the current range of optical training in programs within the traditional non-optics curricula. For the purpose of economy and focus, I have restricted this overview to those institutions that have award bachelor degrees in physics and electrical engineering. While there are other optics programs at other levels, the description and analysis of this selected group will, I think, provide a reasonable description of the type of training being done today. The assessment was carried out by means of a questionnaire sent to 30 schools that award bachelor degrees in physics and electrical engineering. Other data was found in the SPIE publication, "Optics in Education"1. In addition, Ken Cupery of Eastman Kodak made available to me his database, a substantial effort. I extracted those programs from Ken's database and attached the results of my own questionnaire to it. Of the 30 schools I queried I received responses from 21 of them. Two of these indicated that the program was no longer in business, so the results will be based on 19 responses. I am certain I have missed some programs. I apologize to anyone who was overlooked.

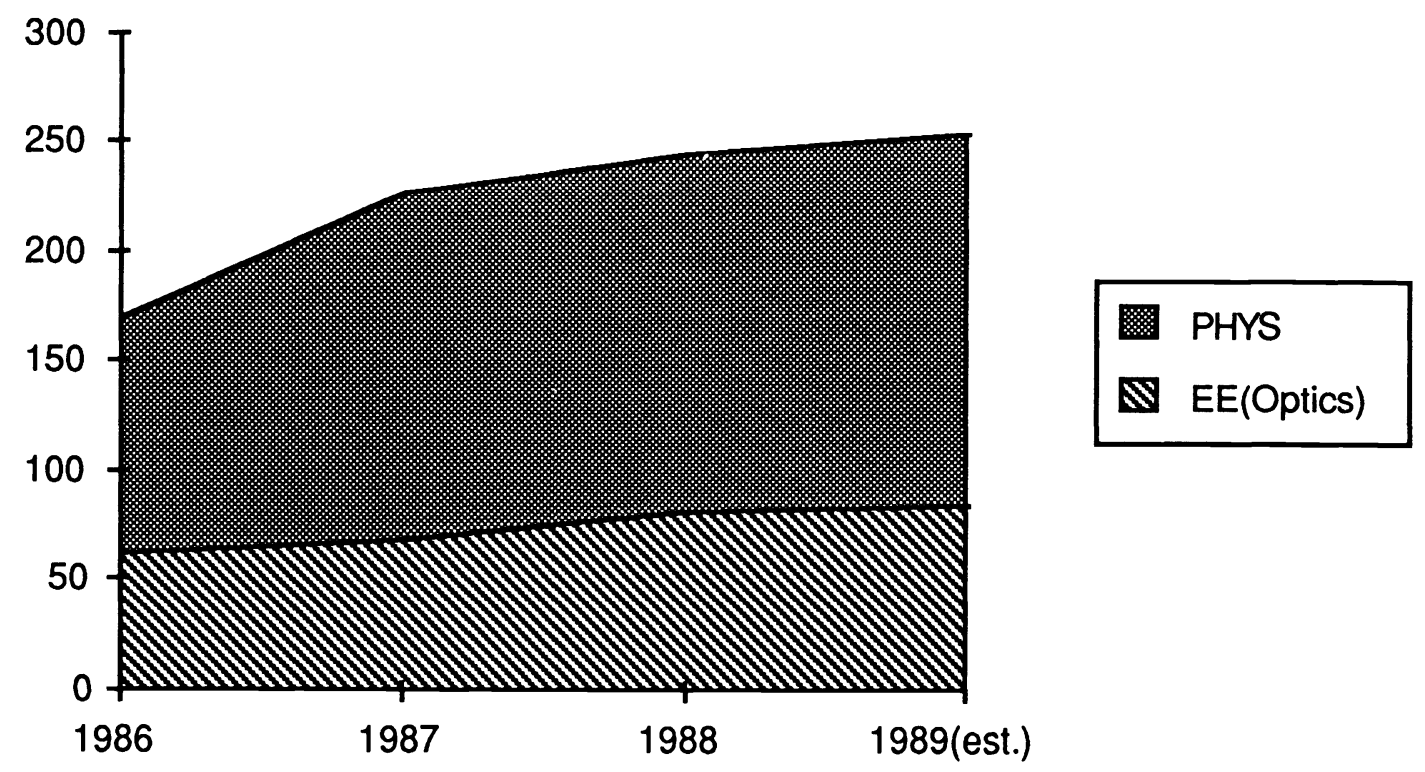

Figure 1. Graduates of traditional non-optics degree programs for the years 1986-1988 and 1989 (estimated). Data does not include any fraction of enrollments from large electrical engineering programs, as noted in text. 


\section{The Numbers}

Despite a some efforts to get good data on the number of students trained in these programs, the variability of training prevents getting the hard numbers that one can acquire from counting those students that graduated with optics or optics-related degrees. (What fractional value do you assign to one of our electrical engineering students at Tech, who takes our jointly taught laser course?) I have organized the data from Ken Cupery's database and from my own questionnaire. If I exclude the large electrical engineering enrollments and sum only those figures from the programs with major course concentrations, I arrive at a series of numbers for the past two years, the current year, and an estimate of next year's graduates. This does not include any attempt at correction for programs that responded but did not provide their enrollment figures. A plot of these figures for these four years is given in Figure 1. The EE school figure is smaller than it should be because I had no way to add the contribution from the the large electrical engineering programs that did not separate out those with optics specialties. The figure shows an increase and a conservative estimate that is slightly below the actual trend of the previous years

If the enrollments for the 1986-87 academic year of schools that grant degrees in optics (University of Rochester, University of Alabama at Huntsville), optical engineering (University of La Verne), applied optics (Rose Hulman Institute of Technology, or imaging science (Rochester Institute of Technology) are totaled, the number is somewhere in the neighborhood of 140 students, with Rochester contributing about $60 \%$ of the total. Based upon these figures and some other analysis, it would appear that currently about half of the bachelor level optics graduates will be trained in non-optics degree programs. This will probably remain true for some time to come unless there is a strong effort on the part of educators and administrators to establish and fund new optics degree programs.

\section{The Optics Education Continuum}

Although there are only a relatively small number of optics programs of the type I want to describe, a description of all of them would be tedious and fail to provide any comparison between them. Rather, I have attempted to put them on a continuum and place some mileposts to describe the some points along it. This continuum extends from specializations that consist of a few courses in optics or related fields within a fairly structured curriculum in the basic field to a substantial offering of courses at the upperclass level. These latter programs are not far removed from a curriculum that would result in an optics, applied optics, or imaging science degree.

The response to one question on the minimum number of courses in optics that the respondents felt were needed to train a student for a "nontechnical/staff/professional position" provided a reasonable definition for these mileposts. With very few exceptions those in semester programs specified four courses and those on quarter systems five or six courses as a minimum. Most seemed to use a three credit-hour per course ratio, so that a program requiring about 12 semester hours or 18 quarter hours represent a concentration in optics. For the purpose of discussion in this paper, programs with substantially less than this will be considered specializations. Those with offerings substantially greater than this will labeled as tracks. In making these definitions, I realize I have just put my two cents into one of the most controversial and strongly defended areas of academic life - someone else's curriculum.

As one might expect, the major division is between those programs based in electrical engineering departments and those in physics departments. The ABET accreditation requirements that are part of any engineering curriculum, restrict the number of elective courses that can be devoted to a special curriculum. In contrast, an unencumbered physics curriculum allows a wide variety of courses, restricted only by the size and interest of the faculty.

Starting with the most limited of these programs, the undergraduate optics component is considered as a useful byproduct of a strong graduate electrical engineering program with an emphasis in optics. As one respondent to the questionnaire put it: "Our undergraduate courses are meant to be introductory courses for our new grad. students. Involving undergraduates in optics in not our main goal, although we are glad to do it too." There are other programs that are somewhat more positive in their reception of undergraduates by involving them in research projects and developing Senior laboratories with a good deal of thought and effort. Usually these programs do not offer a full-fledged concentration, but rather a few courses that they feel will enhance the job prospects of their students. Some take the view that the idea of a separate optics degree is not the correct approach: "We specifically do not have an optics degree because we feel that modern optics is better addressed in the framework of EE. This is because optical engineers need to know optics as well as electronics, semiconductor device physics, systems theory, computers, controls, and network theory."

There are, however, a number of electrical engineering and physics programs that provide more than the introductory course or two. The professors in these programs pride themselves on the amount of special project effort and special topics courses that take advantage of their research expertise in optics. Some of these programs, such as those at the Technical University of Nova Scotia and Stevens Institute of Technology, involve participation by industry in research projects. Many of the smaller programs have managed to put together a minimum curriculum that provides the student with a sufficient concentration to be able to work in an area of optics. Usually they emphasize one field or set of techniques and the students readily find jobs in that area. 
At the other end of the continuum are those schools who offer a rather substantial number of courses, both the elementary courses and special advanced courses. These tracks tend to be concentrated in physics departments not only because of the more flexible curriculum, but also because courses in geometrical and physical optics have in the university catalog for a long time. The upper level courses tend to be in electro-optics, fiber optics, non-linear optics, and holography Some, such as ours at Georgia Tech, offer a certificate in Applied Optics. Most of these programs have one or two electronics courses in their program or available from an electrical/electronic/computer engineering discipline.

All of these programs serve a useful function in providing trained optics personnel. They serve to produce a continuum of training that ranges from the electrical engineer that is comfortable with the demands of the emerging optoelectronics area to the physics students who usually end up as optical engineers once they land on the doorstep of their new industrial homes.

\section{Looking for Answers}

In addition to the question on the minimum size of a concentration in optics, I asked my colleagues some questions about their program and their products $n$ attempt to characterize the bachelor level optics programs in traditional departments.

- Did the program grow out of local demand for persons trained in optics? Only two of the respondents indicated that the programs were begun for this reason. One third said it had a partially responsible for establishment, but the majority indicated that either faculty or student interest was responsible for their program. Despite this fact, most of the programs have involved industry and generated outside support among industry some of it from their own locales.

-Where did their graduates go when they graduate? Most said industry. Two electrical engineering programs and more than half of the physics program indicated their students continued on to graduate school.

- What is their job title? Most respondent including the physics departments said that their students had the title of junior engineer or optical engineer once they were graduated.

- What is their salary? Ken Cupery will have more complete numbers in his presentation. From my questionnaire, I found that those at the bachelor's level in electrical engineering averaged $\$ 30,000$, while the graduates of the physics programs had an average of $\$ 26,000$. This latter figure is a little misleading because two of the programs apparently train technicians. One of these programs listed a salary range of $\$ 16,000-\$ 24,000$, which is considerably lower than any other program in the survey. When this program is removed from the totals, the average is $\$ 27,500$ for the physics program graduates.

\section{The Programs}

Most of the curricula are based upon geometrical and physical courses. Sometimes these are combined, but most schools teach these as separate courses. In some of the specialization courses, a broad-based survey course is used as an introductory course that provides some of the elementary concepts found in the basic courses. After these courses there is usually a course on lasers, which may incorporate non-linear optics and electro-optics. Several of the programs have separate electro-optics courses or laboratories. Most of the programs in electrical engineering departments provide a course and a laboratory on fiber optics. Beyond these general conclusions it is hard to characterize the curricula of these undergraduate programs. The balance of the courses tend to spring from the interests and expertise of individual faculty members.

Most of the respondents for the various programs described those features that they felt were unique in their program. I can say that while some of these features were found in a number of programs, (thus removing that adjective from the feature), the descriptions still provided a look at the current efforts. A majority of the programs indicated that they stressed laboratories and hands-on experiments. At Virginia Polytechnic, the undergraduates in the electrical engineering can take a laboratory that includes operation of an 8-meter fiber draw tower. John Walkup at Texas Tech (EE) described "super Senior projects (semester-long, incorporating design and research)...." E. B Brucker at Stevens (Phys and Eng Phys) listed a Senior Design course, where "student teams start with a design idea (project) and work through the stages to design, build, and evaluate an optical instrument. ...some of the types of projects ... are: a fiber optic magnetometer, a polarimeter, an optical isolator for optical fibers, a cw ruby laser, and a coupler for slab waveguides."

Jeff Davis at San Diego State (Phys) described a single semester optics laboratory. "Students work in groups of 2 for 2 weeks on a single lab. No one else has access to that equipment for the duration of the experiment, making it possible for students to leave a setup, and return to it later in the week. At end of the two week period, students submit a lab report which typically runs 40-50 pages. Students do 7 experiments in the semester at this level." The program also has an independent Senior thesis for each student. Davis is proud of the fact that 9 publications since 1986 have included Senior student coauthors.

I asked if there were any new courses planned for the next two years, since this might give us some idea of the directions that programs at this level are taking. Most often mentioned were courses in fiber optics and electro-optics. Several schools are introducing image processing courses and laboratories. After this the list of new courses includes single efforts in integrated optics, laser spectroscopy, high power lasers, and non-linear optics. 
The graduate of these programs, for the most part, is an apprentice opticker. He or she has a number of the tools and concepts to become productive almost immediately, but, despite our best attempts to provide realistic projects, they lack the practical experience that comes from wrestling with a cantankerous design that was supposed to be finished yesterday. Still, the anecdotal evidence that I gather from my students and my colleagues stories tells me that the training is considerably more than just window dressing. I tell my students that they will almost certainly experience two completely contradictory feelings. First, that of humility because of all the things that they still have to learn; and, second, pride because they will become the local experts in some optical areas since the number of personnel trained in optics is still mighty scarce.

\section{Some Conclusions}

It is clear that non-optics degree programs provide a significant contribution to the training of optical designers and engineers. These programs all have the individual stamp of the faculty who have assembled the curriculum. Most programs recognize the need of hands-on work and try to provide it through a number of laboratories and off-campus involvement.

While only one or two respondents noted it on their questionnaire, there is a generally recognized need for additional faculty members who can teach optics courses, and probably more importantly direct the optics laboratories that everybody agrees are a valuable part of the curriculum. As one who has done this for a number of years, I can testify to the large demands on time that projects and laboratories require.

The students that graduate get good jobs and begin to contribute almost immediately to the projects they work on. The demand should be even greater, but for a strong preference in the optics industry for raiding another company's talent, rather than taking an optics student and providing the experience they need to contribute productively. At time it resembles a baseball league that doesn't acknowledge there are such things as farm teams. Those companies that hire an apprentice opticker and then take the time to treat them professionally will benefit greatly from the output of our programs.

\section{The Future}

There is a tendency in a broad field such as optics to try to cover all our bases. This probably will not happen because of the limited number of faculty that are available to teach and do research. We have to guard against requests for more and more specialized courses. As Jeff Davis noted in his response:

"I am sure that the industry wants a lot of courses on various topics of immediate interest to them. However, I think that we owe the students something more. I want to give them a sufficient base of math, science, and common sense (through the labs) so that they can enter quickly into an industrial environment, become productive quickly, but still have the potential to grow as technology advances. As we increase the number of 'optics' courses, we have to take emphasis away from some other topics, and I don't think that's right"

One small trend that I think I detected in this mass of data (perhaps it is because we at Georgia Tech are examining the possibilities), is that of a need for mutual cooperation between physics and electrical engineering departments. Physics departments, as was noted above, have been giving basic courses in optics for many years and some in recent years have expanded their offerings. Electrical engineering departments have added courses to fields dominated by optical devices, most notably fiber optics and electro-optics. Lasers are up for grabs in most programs, as it is at Tech. It would seem to me that some of the strongest optics programs on the bachelor's level may come from those programs that bridge the gap between the physics and electrical engineering disciplines.

Some programs do, indeed, rely on the other departments. At New Mexico State University Mike Giles notes that there is "excellent cooperation among three departments: EE, ME, and Physics." He notes that "Physics provides many of the courses but not as many undergraduate students. Most undergraduate students are EE's." And Mike Wollman at Cal Poly also noted that his program is interdisciplinary with the Physics department. So, it may be that one of the responses of the academy to the increased needs for optics training is a collaboration between the well-established disciplines of electrical engineering and physics, and, I hope, mechanical engineering. If the problems of workload, curriculum, and other matters must be overcome, then these traditional non-optics programs will continue to play a vital role in producing valuable apprentices in the field of optics.

\footnotetext{
Reference

1"Optics in Education", 1987-88 edition, available from SPIE, Bellingham, WA 98227-0010
} 